\title{
Pressure transient analysis of multiple leakages in a natural gas pipeline
}

\author{
Sunday O. Isehunwa*, Sunday B. Ipinsokan and Oluwatoyin O. Akinsete \\ Department of Petroleum Engineering, University of Ibadan, Ibadan, Nigeria.
}

Received 16 September, 2013; Accepted 31 December, 2013

\begin{abstract}
Pipelines are principal devices for natural gas transportation which are amenable to operational challenges such as leakages. Several methods for predicting leakages in natural gas pipeline have been developed. Some of these techniques detect leakages after several hours while some are prone to false alarms or inaccurate predictions. This study developed a pressure transient analysis model for predicting gas pipeline leakages in real time. The method of characteristics was employed to solve the resultant non-linear gas flow equations without neglecting the inertia term as in previous studies. The system behaviour was simulated after discretizing the pipe length and the differences between observed and calculated variables were used to predict single and multiple leakages. Results were validated using field data.
\end{abstract}

Key words: Pipeline leakages, natural gas, pressure transient, analytical method, method of characteristics.

\section{INTRODUCTION}

Pipeline networks are essential infrastructure in modern transportation of natural gas. Material defects, temperature and pressure changes, bad maintenance, corrosion, sabotage action, and other factors can lead to leaks with consequent economic, environmental, and safety implications. Therefore, leak detection and location methods are keys in the overall integrity management of pipeline systems. The efficiency of a leak detection system can be assessed using parameters such as leak sensitivity, location estimating accuracy, ease of operation, availability, false alarm rate, maintenance requirement and cost.

Pipeline leakages can be defined based on the magnitude of the leak flow and on the way the leak flow develops. Leak prediction or detection methods can be classified into hardware based methods, biological methods and software based methods. Eisler et al. (2012) grouped leak detection methods as internal-type and external-type leak detection systems. External-type methods are used for routine surveillance of pipelines rather than continuous monitoring (Zhanget al., 2013). The external-type has reduced applicability in deep subsea conditions.

Acoustic monitoring techniques utilize acoustic detectors to predict the wave of noise which will be generated as the gas escapes from the pipeline (Barbagelata, 2011; Brodetsky and Savic, 1993; Klein, 1993). They are simple and accurate, and can predict relatively small leaks. However, a large number of acoustic sensors along the pipeline are required, which will increase the cost. If the leaks are too small to produce acoustic signals at levels substantially higher than the background noise, this technology will be useless (Walker, 2011; Sivathanu, 2003).

Optical monitoring methods can be classified as either passive or active (Reichardt et al., 1999). Active methods

*Corresponding author. E-mail: sunday.isehunwa @gmail.com.

Author(s) agree that this a rticle rema in permanently open access under the terms of the Creative CommonsAttribution License 4.0 Intemational License 
involve the illumination of the area above the pipeline with a radiation source, usually a laser or a broad band source. Then the absorption or scattering caused by gas molecules above the surface is monitored using an array of sensors at specific wavelengths (Iseki et al., 2000; Spaeth and O'Brien, 2003). In contrast to active methods, passive methods do not require a source. They detect the radiation emitted by the natural gas, or the background radiation serves directly. Optical monitoring techniques can be used for moving vehicles, aircraft, portable systems, or on site, and are able to monitor the pipeline over an extended range. Moreover, they have high spatial resolution and sensitivity under specific conditions. But for most optical methods, the implementation cost is high. High false alarm rate is another disadvantage.

Liquid sensing cables (Alaskan Department of Environmental Conservation [ADEC], 2000) are buried beneath or adjacent to pipelines and are designed to reflect changes in transmitted energy pulses as a result of impedance differentials induced by contact with hydrocarbon liquids. Safe energy pulses are continuously sent by a microprocessor through the cable. Advantages include relatively high accuracy in determining leak location, no modifications to existing pipeline, and easy software configuration and maintenance. Disadvantages include very high installation costs and extensive power and signal wiring requirements.

Sampling methods are mostly used to detect hydrocarbon gas leaks (Sperl, 1991). The sampling can be done by carrying a flame ionization detector along a pipeline or using a sensor tube buried in parallel to the pipeline. Very tiny leaks can be detected using these methods. The response time varies from several hours to days, and the cost of monitoring long pipelines is very high. The method does not function for exposed pipelines, and it is very expensive because the trace chemical needs to be added to the gas continuously.

Flow monitoring methods rely on pressure and/or flow signals at different sections of a pipeline. When the pipeline operates normally, there are some steady relationships among these signals. Changes in these relationships will indicate the occurrence of leaks. Volume balance is the most straightforward flow monitoring method. A leak alarm will be generated when the difference between upstream and downstream flow measurements changes by more than an established tolerance (Ellul, 1989). But because of the inherent flow dynamics and the superimposed noise, only relatively large leaks can be detected. Wang et al. (1993) formulated the pressure gradients by using the autoregressive (AR) model. Using this model, some improvement in the leak prediction capability could be achieved.

The magnetic flux leakage method periodically inspects the pipeline for damages using a 'pig', which is launched at the inlet and retrieved at the outlet. The pig employs the magnetic flux leakage (MFL) technique for assessing the condition of the pipe (Afzal and Udpa, 2002). This method is functional only for a seamless gas pipeline, and leaks cannot be detected continuously.

The Particle Filter (PF), proposed by Gordon et al. (1993) uses sequential Monte-Carlo methods to approximate the optimal filtering by representing the probability density function (PDF) with a swarm of particles. The method is able to handle any functional nonlinearity system or noise of any probability distribution hence it has attracted much attention (Bolviken et al., 2001; Doucet et al., 2000; Kitagawa, 1996).

The working principle of mass balance method for leak detection is straightforward. If a leak occurs, the mass balance equation presents a systematic deviation. Although simple and certainly reliable, the primary difficulty in implementing this principle in practice derives from the huge variations experienced by the line pack term. This effect implies a very long detection time. The principle is also very sensitive to arbitrary disturbances and dynamics of pipelines and may lead to false detections (Eisler et al., 2012; Eisler, 2011). Billmann and Isermann (1987) and Shields et al. (2001) have used a nonlinear state observer and a special correlation technique for leak detection. Other authors (Benkherouf and Allidina, 1988; Zhou and Frank, 1995; Zhao and Zhou, 2001) have developed similar techniques to predict and locate leaks, with an improved detection speed. Tiang (1997) used thermal methods.

In simulating transient flow of single-phase natural gas in pipelines, most of the previous investigators neglected the inertia term in the momentum equation. This renders the resulting set of partial differential equations linear. Numerical methods previously used to solve this system of partial differential equations include the method of characteristics (MOC) and a variety of explicit and implicit finite difference schemes (Wylie et al., 1971; Streeter and Wylie, 1970; Liou, 1989; Wylie and Streeter, 1993; Bergant et al., 2001; Kim, 2005). Neglecting the inertia term in the momentum equation will definitely result in loss of accuracy of the simulation results. In order to compensate for the absence of the inertia term in the momentum equation, Yow introduced the concept of "inertia multiplier" to partially account for the effect of the inertia term in the momentum equation. Wylie et al. (1971) simulated transients in natural gas pipelines in accordance with the concept of "inertia multiplier" which sometimes yield very misleading results. This study used the MOC to linearize the nonlinear hydraulic equations, which was then solved analytically.

\section{THEORETICAL FRAMEWORK}

It was assumed that temperature is constant because the heat lost to the environment as a result of work done is negligible; this assumption is valid for short pipelines. The flow of gas through the 
pipeline was modelled under the following assumptions:

1. The flow is isothermal.

2. Axial molecular and eddy transport is negligible in comparison with the bulk transport.

3. Steady-state friction correlations are valid.

4. The pipe has a constant cross-sectional area over any increment $d x$.

The governing unsteady pipe flow equations can be expressed as:

$\frac{\partial P}{\partial t}+c^{2} \frac{\partial(\rho u)}{\partial x}+\frac{\partial(\rho u)}{\partial t}+\frac{\partial\left(\rho u^{2}+P\right)}{\partial x}=F_{f}+F_{g}$

By regrouping Equation 1, we have:

$\frac{\partial P}{\partial t}+\frac{\partial(\rho u)}{\partial t}+c^{2} \frac{\partial(\rho u)}{\partial x}+\frac{\partial\left(\rho u^{2}+P\right)}{\partial x}=F_{f}+F_{g}$

Or,

$\frac{\partial(P+\rho u)}{\partial t}+c^{2} \frac{\partial(\rho u)}{\partial x}+\frac{\partial\left(\rho u^{2}+P\right)}{\partial x}=F_{f}+F_{g}$

Equation (3) can be represented as:

$\frac{\partial v}{\partial x}+\frac{\partial F}{\partial x}+D=0$
And

$\rho u=m=m_{o}$

Where $m_{O}$ is the mass flux at the inlet of pipeline which is the product of the gas density and gas velocity is constant along the pipeline.

The one dimensional (Zhou and Adewumi, 1995) form of the momentum for gas flow in horizontal pipelines with spatially invariant temperature is given by Equation 6:

$\frac{\partial\left(\rho u^{2}\right)}{\partial x}+\frac{\partial P}{\partial x}=-\frac{f_{g} m_{O}^{2}}{2 D \rho}$

For inclined or vertical natural gas pipeline with spatially invariant temperature distribution along pipeline, Equation 6 can be modified by introducing gravitational factor to give:

$\frac{\partial\left(\rho u^{2}\right)}{\partial x}+\frac{\partial P}{\partial x}=-\frac{f_{g} m_{o}^{2}}{2 D \rho}-\frac{P g \sin \alpha}{c^{2}}$

By substituting terms and solving, gas flow in inclined pipelines can be described by Equation 8:

For horizontal pipelines, $(\propto-\theta)$ and there is a discontinuity in the

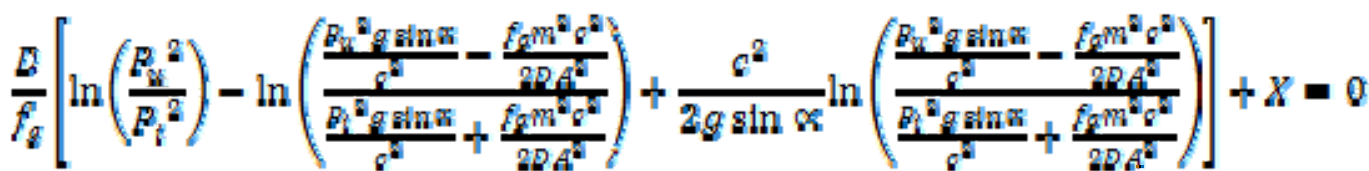

second term of L.H.S. of Equation (8). The singularity at $\mathbf{Q m} \mathbf{0}$ can be removed by applying L'Hopital's Rule:

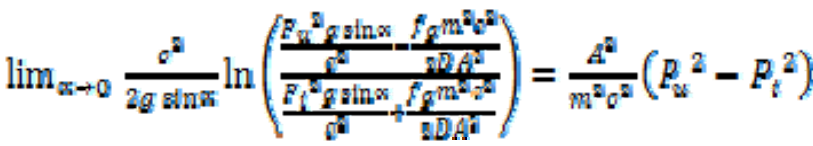

Hence, substituting $Q$ and Equation 9 into Equation 8 gives for horizontal pipelines:

$\frac{D}{f_{g}}\left[\ln \left(\frac{P_{O}^{2}}{P_{i}^{2}}\right)+\frac{A^{2}}{m^{2} c^{2}}\left(P_{O}^{2}-P_{i}^{2}\right)\right]+X=0$

Where $P_{O}$ and $P_{i}$ are the outlet and inlet pressure respectively as shown in Figure 1 and $X$ is the length of the pipe and discharge rate $Q$. Equation 10 becomes:

$\frac{D}{f_{g}}\left[\ln \left(\frac{P_{o}^{2}}{P_{i}^{2}}\right)+\frac{A^{2}}{Q^{2} \rho^{2} c^{2}}\left(P_{o}^{2}-P_{i}^{2}\right)\right]+X=0$

\section{RESULTS AND DISCUSSION}

Equation 8 can be considered as a generalized expression for isothermal gas flow in gas pipelines.
It describes the functional relationship between inlet gas pressure, outlet gas pressure, gas mass flux, friction factor, sound speed, diameter, and the length of pipeline. On the other hand, Equation 11 gives the particular expression for horizontal pipelines. These equations are not explicit in pressure but can be solved using the Newton Raphson iterative method and used to predict leakages in gas pipelines. When leak occurs at any point in a pipeline, there is a sudden change in pressure and flow characteristics. For example, there is a sudden pressure drop in the pipe at the location of the leak followed by rapid line depressurization a few seconds (or milliseconds) later.

Thus mathematically,

$P_{S}-P_{M}=\beta$

Where $P_{z}$ is the expected or simulated pressure at every joint of the pipeline while $P_{M}$ is the observed or measured pressure (Figure 2).

Subsequently for a decision on occurrence of leakage, we have the condition:

$\beta\left\{\begin{array}{l}\leq 0 ; \quad \text { No leakage } \\ \text { oi There ts leakage }\end{array}\right.$ 


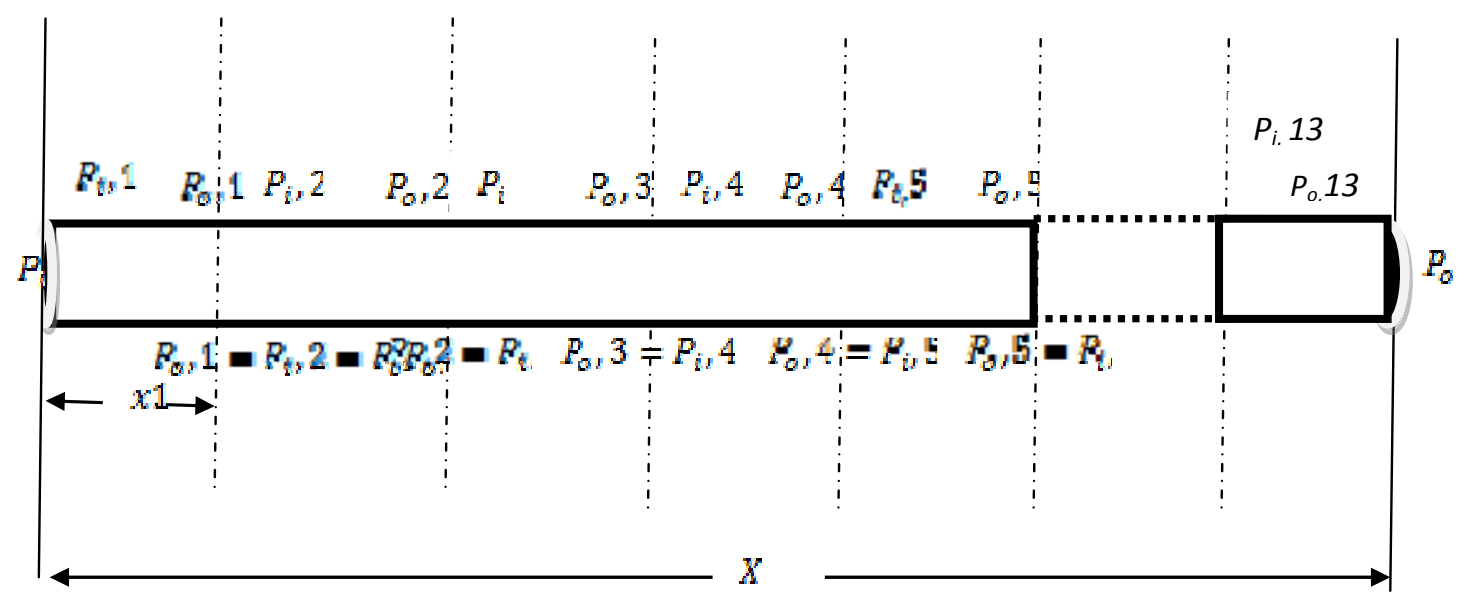

Figure 1. Division of pipe into computational segments.

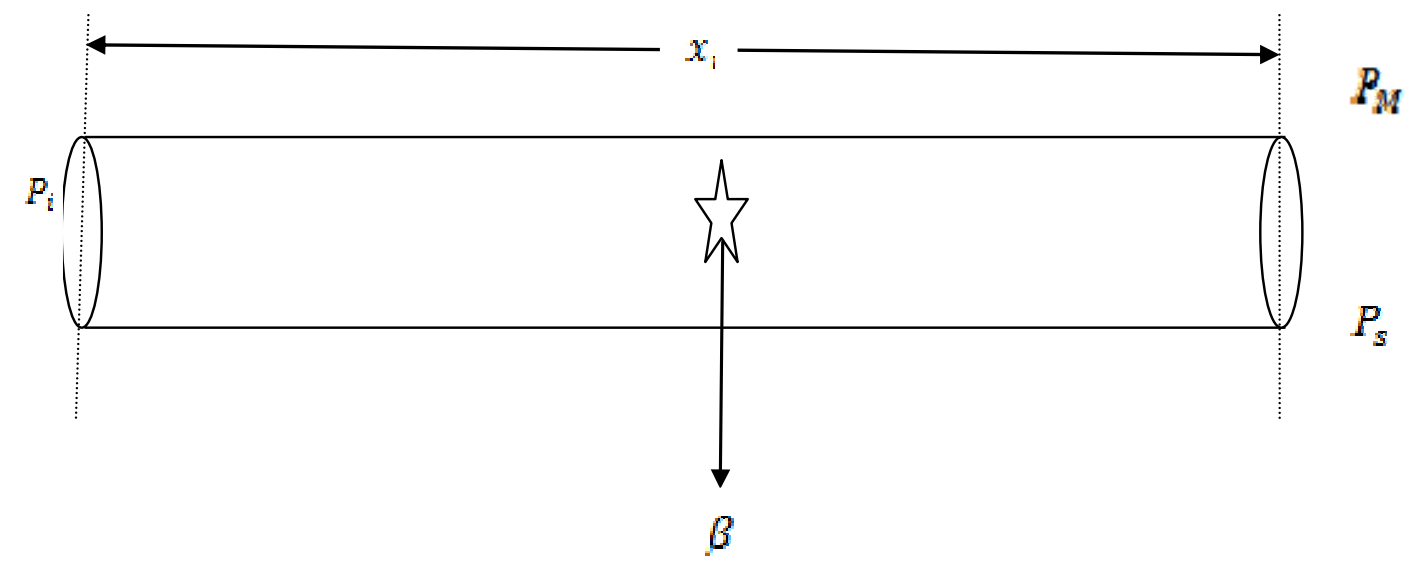

Figure 2. Leakage at a section of the pipeline.

The pressure difference at every point (Equation 12) can be computed if the pressure profile Ps is known at the initial stage before leakages, while the value of $P_{M}$ at every point $X_{i}$ must be available through the automatic measuring device. It then follows that a value of $\beta$ a indicate leakage at a location just before the next point.

When multiple leakages occur, the transient effects created by each leakage will arrive the outlet at different times. Hence we suggest that in applying Equations 8 and 11 , leakages should be treated sequentially.

In order to demonstrate the validity of this method, some simulation tests were carried out using the horizontal pipeline case. The first test was to show the accuracy of the model by comparing measured pressure with the simulated pressure. The second test showed the effect and possible position of a leakage. The last test was to predict multiple leakages in the chosen segments. The essential parameters used in the simulation are as follows: A pipeline length of 48.28 miles $(83.2 \mathrm{~km})$, diameter of 8.15 inches, temperature of $510^{\circ} \mathrm{R}$, frictional factor of 0.009 , gas density of 0.69 , flow rate of 0.75 MMscf/h, 13 segments.

Tables 1 and 2 compare the simulated results from Equation 12 with the measured results; the results were also shown in Figures 3, 4 and 5. Table 1 shows the results of the first simulated test. The total length of the pipe was divided into 13 segments and the measured pressures were used to calculate gas compressibility factor for each segment. The simulated or calculated values are in very good agreement with field data. This shows the accuracy of the model. The result is also represented in Figure 3.

The second simulation was to show the effect of leakage on the pressure. The results are shown in Figure 4. There was pressure loss between the 5th and the 6th sections; indicating that there was leakage. It was estimated that the leak occurred at 18.23 miles of the pipe line.

The third scenario was demonstrated by analyzing behaviour over $12 \mathrm{~h}$ on an hourly basis as shown in Table 2. In the second hour the first and second leaks 
Table 1. Comparison of simulated with measured results: Single leakage case.

\begin{tabular}{ccccc}
\hline Node & Pipe length (miles) & Z - Factor & Measured pressure (Psia) & Simulated pressure (Psia) \\
\hline 1 & 0.000 & 0.901520 & 700 & 700.00 \\
2 & 4.023 & 0.900921 & 694 & 694.09 \\
3 & 8.046 & 0.900314 & 688 & 688.08 \\
4 & 12.069 & 0.900008 & 685 & 682.06 \\
5 & 16.092 & 0.899494 & 680 & 679.05 \\
6 & 20.115 & 0.898766 & 673 & 674.04 \\
7 & 24.138 & 0.898135 & 667 & 667.02 \\
8 & 28.162 & 0.897709 & 663 & 661.01 \\
9 & 32.185 & 0.897174 & 658 & 657.00 \\
10 & 36.208 & 0.896524 & 652 & 651.99 \\
11 & 40.231 & 0.895758 & 645 & 645.97 \\
12 & 44.254 & 0.895204 & 640 & 638.96 \\
13 & 48.277 & 0.894646 & 635 & 633.95 \\
\hline
\end{tabular}

Table 2. Measured and simulated pressure distribution over time for multiple leakages.

\begin{tabular}{|c|c|c|c|c|c|c|}
\hline \multirow{2}{*}{$\begin{array}{c}\text { Time } \\
\text { (h) }\end{array}$} & \multicolumn{2}{|c|}{ Section A } & \multicolumn{2}{|c|}{ Section B } & \multicolumn{2}{|c|}{ Section C } \\
\hline & $\mathbf{P}_{M}$ (Psia) & Ps (Psia) & $\mathrm{P}_{\mathrm{M}}$ (Psia) & $P_{s}$ (Psia) & $P_{M}$ (Psia) & $\mathrm{Ps}_{\mathrm{s}}$ (Psia) \\
\hline 1 & 950 & 950.00 & 938 & 938.01 & 921 & 921.01 \\
\hline 2 & 947 & 944.77 & 935 & 932.73 & 916 & 915.67 \\
\hline 3 & 940 & 941.76 & 930 & 929.72 & 910 & 910.66 \\
\hline 4 & 930 & 934.74 & 924 & 924.71 & 904 & 904.64 \\
\hline 5 & 927 & 924.71 & 919 & 918.69 & 897 & 898.62 \\
\hline 6 & 920 & 921.70 & 912 & 913.68 & 892 & 891.60 \\
\hline 7 & 917 & 914.68 & 908 & 906.65 & 885 & 886.59 \\
\hline 8 & 912 & 911.67 & 903 & 902.64 & 880 & 879.56 \\
\hline 9 & 907 & 906.65 & 898 & 897.63 & 874 & 874.55 \\
\hline 10 & 903 & 901.64 & 892 & 892.61 & 868 & 868.53 \\
\hline 11 & 896 & 897.63 & 850 & 890.59 & 845 & 845.51 \\
\hline 12 & 887 & 886.48 & 846 & 844.46 & 841 & 839.45 \\
\hline \multirow{2}{*}{$\begin{array}{c}\text { Time } \\
\text { (h) }\end{array}$} & \multicolumn{2}{|c|}{ Section D } & \multicolumn{2}{|c|}{ Section E } & \multicolumn{2}{|c|}{ Section $\mathrm{F}$} \\
\hline & $P_{M}$ & $P_{s}$ & $P_{M}$ & $P_{s}$ & $P_{M}$ & $P_{s}$ \\
\hline 1 & 910 & 910.02 & 893 & 892.97 & 872 & 972.02 \\
\hline 2 & 880 & 904.65 & 866 & 887.60 & 855 & 954.53 \\
\hline 3 & 875 & 874.56 & 861 & 860.51 & 852 & 951.49 \\
\hline 4 & 871 & 869.54 & 855 & 855.50 & 847 & 946.47 \\
\hline 5 & 865 & 865.53 & 850 & 849.48 & 842 & 841.46 \\
\hline 6 & 860 & 859.51 & 844 & 844.46 & 837 & 836.44 \\
\hline 7 & 856 & 854.49 & 840 & 838.45 & 834 & 831.42 \\
\hline 8 & 851 & 850.48 & 836 & 834.43 & 830 & 828.42 \\
\hline 9 & 844 & 845.47 & 832 & 830.42 & 825 & 824.40 \\
\hline 10 & 840 & 838.45 & 827 & 826.41 & 820 & 819.39 \\
\hline 11 & 815 & 835.06 & 792 & 821.39 & 775 & 774.37 \\
\hline 12 & 810 & 809.32 & 787 & 786.29 & 771 & 769.24 \\
\hline
\end{tabular}

occurred within segments $C$ and $D$ respectively. The third leak was initiated within the segment $A$ at the upstream section of the pipeline at the 11 th $\mathrm{h}$. The impacts of the three leaks were felt in the 4th segment. Figure 5 demonstrates different patterns of the deviations between the predicted and simulated pressures in natural gas pipeline. 


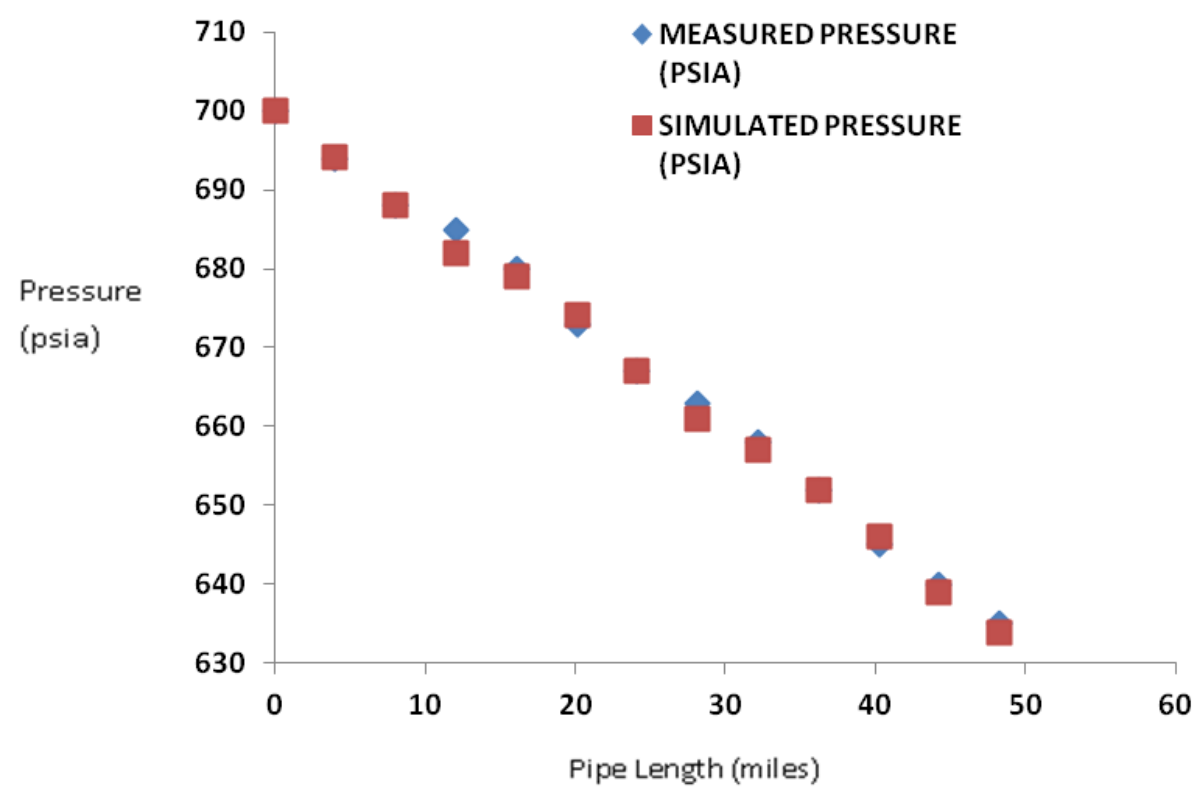

Figure 3. Plot of simulated and measured pressure vs. pipe length.

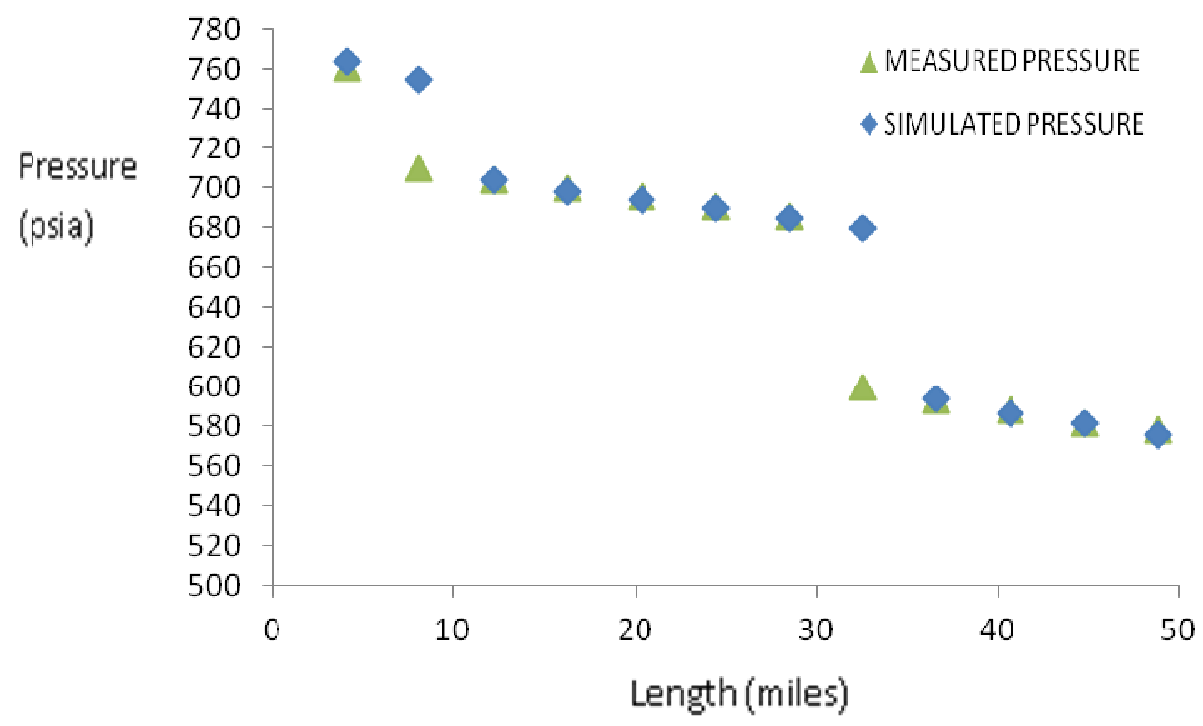

Figure 4. Prediction of multiple leakages on unit data taken at each section of the pipe.

\section{Conclusion}

The study revealed:

1) A novel approach for predicting leakages was developed based on analysis of continuous pressure measurement at segments of the pipeline. The method shows promise for efficient real time leak prediction and probably location of leakage in pipeline.

2) The technique has proven to be effective for the prediction of single and multiple leakages with good results.
3) When severe transients exist short time steps should be taken, and for slow transients higher ones are recommended. The optimal placing of pressure measurement device should be considered very well by first analysing the transient flow in the pipeline.

\section{Nomenclature}
A: $\quad$ Cross sectional area of pipe $\left(\mathrm{ft}^{2}\right)$
C: $\quad$ Velocity of sound
D: $\quad$ Inside diameter of pipe (inches) 


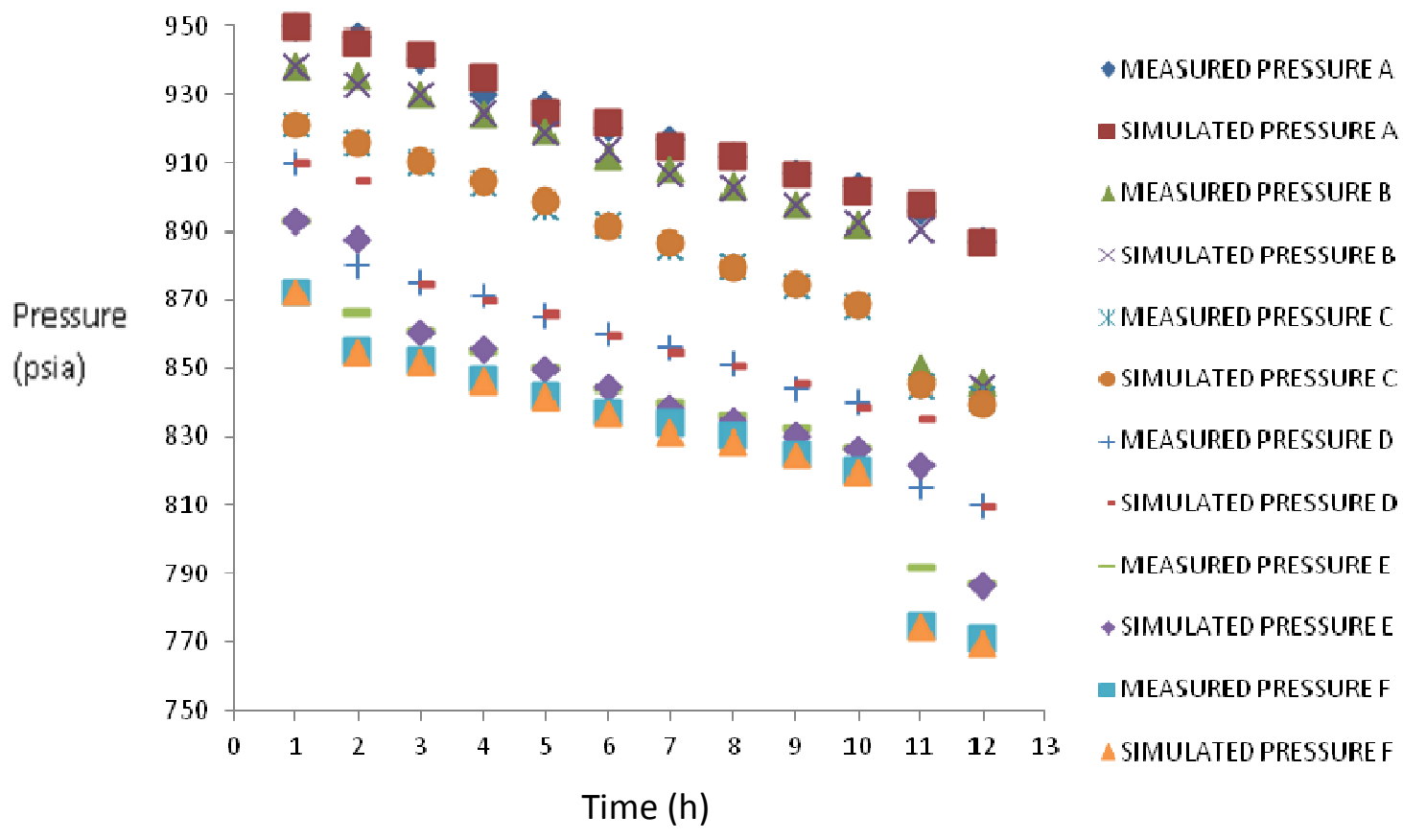

Figure 5. Pressures distribution over time to predict multiple leakages.

f: $\quad$ Friction factor

g: $\quad$ Acceleration due to gravity $\left(\mathrm{ft} / \mathrm{s}^{2}\right)$

$\mathrm{m}: \quad$ Mass flux

$P_{\mathrm{i}}$ : $\quad$ Inlet pressure (psia)

$\mathrm{P}_{\mathrm{O}}$ : $\quad$ Outlet pressure (psia)

$\mathrm{Q}: \quad$ Volumetric flow rate $\left(\mathrm{ft}^{3} / \mathrm{s}\right)$

$\mathrm{U}: \quad$ Velocity of fluid $(\mathrm{ft} / \mathrm{s})$

$\mathrm{X}: \quad$ Length of pipe (miles)

$\alpha: \quad$ Pipeline angle $\left({ }^{\circ}\right)$

$\rho: \quad$ Density $\left(\mathrm{ibm} / \mathrm{ft}^{3}\right)$.

\section{Subscripts}

$\begin{array}{ll}\text { g: } & \text { Gas; } \\ \text { i: } & \text { Inlet; } \\ \text { u: } & \text { Outlet; } \\ \text { M: } & \text { Measured; } \\ \text { S: } & \text { Simulated; } \\ \text { i : } & 1,2,3 \ldots 7 .\end{array}$

\section{Conflict of Interests}

The author(s) have not declared any conflict of interests.

\section{REFERENCES}

Afzal M, Udpa S (2002). Advanced signal processing of magnetic flux leakage data obtained from seamless gas pipeline. NDTandE Int. 35(7):449-457.

Alaskan Department of Environmental Conservation, ADEC (2000).
Technical Review of Leak Detection Technologies, Crude-oil Transmission Pipelines Research Report 1.

Barbagelata L (2011). Accoustic Leak Detector Underwater Acoustic for Leak Detection. Subsea and Arctic Leak Detection Symposium (SALDS), Houston, TX.

Benkherouf A, Allidina AY (1988). Leak detection and location in gas pipelines. IEE Proc. 35(2):142-148.

Bergant A, Simpson AR, Vitkvsky JP (2001). Developments of Unsteady pipe flow friction modelling. J. Hydr. Res. IAHR 39(3):249-257.

Billmann L, Isermann R (1987). Leak detection methods for pipelines. Automatica 23(3):381-385.

Bolviken E, Acklam PJ, Christiphersen N, Stordal JM (2001). MonteCarlo filters for non-linear state estimation. Automatica 37(2):177-183.

Brodetsky E, Savic M (1993). Leak monitoring system for gas pipelines. IEEE Int. Conf. Acoust. Speech Sig. Process. Minneapolis, USA 3:1720.

Doucet A, Godsill S, Ardrieu C (2000). On sequential Monte-Carlo sampling methods for Bayesian filtering. Statist. Comput. 10(3):197208.

Eisler B (2011). Leak Detection systems and Challenges for Arctic Subsea Pipelines. Arctic Technology Conference, Paper 22134, February.

Eisler B, Genesis, Lanan GA (2012). Fiber Optic Leak Detection Systems for subsea Pipelines. Offshore Technology Conference (OTC), Texas, USA, 30 April-3 May.

Ellul I (1989). Pipeline Leak Detection. Chem. Eng. P. 461.

Gordon NJ, Salmond DJ, Smith AFM (1993). Novel approach to nonlinear/non-Gaussian Bayesian state estimation. IEE Proc. 140(2):107-113.

Iseki T, Tai H, Kimura K (2000). A portable remote methane sensor using a tunable diode laser. Meas. Sci. Technol. 11(6):594-602.

Kim SH (2005). Extensive development of leak detection algorithm by impulse response method. J. Hydraul. Eng. ASCE 131(3):201-208

Kitagawa G (1996). Monte-Carlo filter and smoother for non- Gaussian nonlinear state space models. J. Comput. Graph. Statist. 5(1):1-25.

Klein WR (1993). Acoustic Leak Detection. Am. Soc. Mech. Eng. Petrol. Div. (Publication) PD 55:57-61.

Liou JC (1998). Pipeline Leak Detection by Impulse Response Extraction. J. Fluids Eng. ASME 120:833-838. 
Reichardt TA, Einfield W, Kulp TJ (1999). Review of remote detection for natural gas transmission pipeline leaks.

Shields DN, Ashton SA, Daley S (2001). Design of nonlinear observers for detecting faults in hydraulic sub-sea pipelines. Contr. Eng. Pract. 9(3):297-311.

Sivathanu Y (2003). Natural Gas Leak Detection in Pipelines. Technology Status Report, En'Urga Inc., West Lafayette, IN.

Spaeth L, O'Brien M (2003). An additional tool for integrity monitoring. Pipeline Gas J. 230(3):41-43.

Sperl JL (1991). System pinpoints leaks on Point Arguello offshore line. Oil Gas J. 89(36):47-52.

Streeter VL, Wylie EB (1970). Natural Gas Pipeline Transients. Sot. Pet. Eng. J. 75:357-364.

Tiang $X$ (1997). Non-isothermal long pipeline leak detection and location. Atca Scientiarum Naturalium Universitis Pekinensis 33(5):574-580.

Walker I (2011). Leak Detection using Distributed Acoustic Sensing. Subsea and Arctic Leak Detection Symposium (SALDS), Houston, TX.

Wang G, Dong D, Fang C (1993). Leak detection for transport pipelines based on autoregressive modelling. IEEE Trans. Instrum. Meas. 42(1):68-71.

Wylie EB, Streeter VL (1993). Fluid Transients in Systems. Englewood Cliffs: Prentice-Hall.

Wylie EB, Stoner MA, Streeter VL (1971). Network System Transient Calculation by Implicit Methods. SPEJ 3:356-362.
Zhang J, Hoffman A, Murphy K, Lewis J, Twomey M (2013). Review of Pipeline Leak Detection Technologies. Pipeline Simulation Interest Group (PSIG). PSIG Annual Meeting, Prague, Czech Republic, Paper PSIG 1303, 16-19 April.

Zhao Q, Zhou DH (2001). Leak detection and location of gas pipelines based on a strong tracking filter. Trans. Contr. Automat. Syst. Eng. 3(2):89-94.

Zhou DH, Frank PM (1996). Strong tracking filtering of nonlinear timevarying stochastic systems with colored noise with application to parameter estimation and empirical robustness analysis. Int. J. Contr. 65(2):295-307.

Zhou J, Adewunmi MA (1995). The Development and Testing of a New Flow Equation. Pipeline Simulation Interest Group 27th Annual Meeting Albuquerque, NM. 